\title{
Identifying Early Extraperitoneal High-Volume Urine Leak Post Kidney Transplantation
}

\author{
Authors: \\ Brian Mark Churchill," Ajay Sharma, ${ }^{2,3}$ Davis Aziz,4 *Ahmed Halawa ${ }^{2,5}$ \\ 1. IQVIA, Bangalore, India \\ 2. Postgraduate Education in Transplantation, University of Liverpool, Liverpool, UK \\ 3. Department of Transplantation, Liverpool University Teaching Hospitals NHS \\ Foundation Trust, Liverpool, UK \\ 4. School of Medicine, University of Liverpool, Liverpool, UK \\ 5. Sheffield Kidney Institute, Sheffield Teaching Hospitals, Sheffield, UK \\ *Correspondence to ahmed.halawa@liverpool.ac.uk \\ Disclosure: $\quad$ Dr Churchill is an employee of IQVIA, a contract research organisation. The other \\ authors have declared no conflicts of interest. \\ Received: \\ 10.08.20 \\ Accepted: \\ 27.10 .20 \\ Keywords: \\ Extraperitoneal urine leak, lymphocele, perinephric abscess, seroma, \\ urinary fistula, urinoma. \\ Citation: \\ EMJ. 2021; DOI/10.33590/emj/20-00213.
}

\begin{abstract}
Transplant clinicians need to be watchful of several potential surgical complications in the early post-transplant period, including haemorrhage, extraperitoneal urine leak, and lymphocele. While haemorrhage and extraperitoneal urine leak usually present in the early post kidney transplant period, lymphoceles usually present 2-6 weeks after transplantation. While the colour and volume of the drained fluid can give some indication of the problem, is not enough evidence for a confident urine leak diagnosis. Further investigations, such as serum biochemical parameter analysis of the drained fluid and ultrasonography, help to identify the true cause. This paper discusses how to identify high-volume extraperitoneal urine leaks in the early post kidney transplant period and considers the differential diagnoses. Different ureteroneocystostomy procedures, including the Lich-Grégoir, Politano-Leadbetter, and U-stitch techniques, are discussed and compared regarding complication rates (especially urine leak and haematuria). The authors also address the management of low- and high-volume extraperitoneal urine leak, the follow-up needed, and the impact of urine leak on graft and patient survival, length of hospital stay, and rate of hospital readmission.
\end{abstract}

\section{INTRODUCTION}

The first few days after kidney transplantation are the most critical in determining the fate of the graft and the recipient. The clinical team is extremely vigilant in monitoring parameters that could indicate graft dysfunction, graft rejection, delayed graft function, post-operative complications, drug levels (especially tacrolimus or cyclosporine level), infection, and the general wellbeing of the kidney transplant recipient (KTR) and donor. Urine leak is an early post-operative complication after kidney transplantation and occurs in 1.2-8.9\% of these operations. Low-volume leaks may subside with conservative management and provided there is no distal obstruction. If not resolved, or if it is large-volume urine leak, surgical exploration and 
correction may be needed. This article discusses the identification of extraperitoneal urinary leak in a KTR in the post-operative period, as well as the clinical clues that help to rule out the differential diagnoses.

\section{URETEROVESICAL ANASTOMOSIS AND A COMPARISON OF ASSOCIATED COMPLICATIONS}

Many different techniques are used to achieve ureterovesical anastomosis in kidney transplantation., ${ }^{1,2}$ The most popular methods include the Lich-Grégoir, Politano-Leadbetter, and U-stitch techniques. ${ }^{2-5}$ Meta-analyses performed by Alberts et al. ${ }^{2}$ showed that the Lich-Grégoir technique is significantly associated with a lower incidence of urinary leakage compared to the Politano-Leadbetter technique. The analyses also showed significantly fewer incidences of haematuria with the Lich-Grégoir method than both the Politano-Leadbetter and U-stitch techniques, regardless of ureteral stenting. The investigators concluded that the Lich-Grégoir technique results in fewer urological complications than the other two ureterovesical anastomosis procedures. ${ }^{2}$ Whichever technique is used, in order to prevent reflux during voiding, the ureterovesical anastomosis must be tension-free and protected by at least a $1 \mathrm{~cm}$ submucosal tunnel.'

\section{UROLOGICAL COMPLICATIONS DURING THE POST-OPERATIVE PERIOD IN KIDNEY TRANSPLANT RECIPIENTS}

The most common surgical urology complications include urine leakage, ureteral obstruction, and lymphocele (fluid collection between the urinary bladder and the kidney allograft). ${ }^{6}$ The rates of urological complications range from $2.5 \%$ to $30.0 \%$ of all recipients. ${ }^{6}$ In cases of urine leak, the patient may have a fever, pain over the graft, and fluid leakage from the wound. Routine prophylactic intraoperative stenting of the ureter in kidney transplant recipients mitigates the effects of ureteric complications but does not reduce the incidence of these complications. The stents are generally well tolerated, but when longer stents are used (stent length: $\geq 20 \mathrm{~cm}$ ), or if used for longer periods (>6 weeks), they may result in stent-related complications including infection, migration, and encrustation. ${ }^{7}$ The initial step in urine leak management is to maximally decompress the urinary system. This is achieved by inserting a urethral catheter, as well as performing a nephrostomy or placing an antegrade ureteric stent. The drain is left in situ. If this technique fails, or if large-volume extravasation occurs, surgical exploration to reimplant the transplant ureter becomes necessary. ${ }^{8}$

\section{Other urological complications include:9,10}

> Complications caused by the length of the transplanted ureter. A long ureter is liable to kinking and obstruction as a result of ischaemia because the vascularity of the transplant ureter depends on renal vessels supplying through periureteric tissue, unlike the native ureter which has a segmental blood supply. A short ureter may not be appropriate for achieving tension-free anastomosis.

> Atrophic bladder or dysfunctional bladder in the recipient may result in bladder perforation or anastomotic dehiscence. ${ }^{11}$

> Proximal calyceal leak may occur because of lower pole artery complications (thrombosed, ligated, not reconstructed). ${ }^{12-14}$

> Damage to the ureter during dissection may result in ureteric ischaemia, necrosis, and distal leak. ${ }^{15,16}$

Urological complications in the post-operative period can be identified by the drained fluid's colour (clear, haemorrhagic, or purulent) and odour (uriniferous or foul)..$^{17}$ If there is a delayed graft function, a urinary leak can be detected only after the urine output increases. ${ }^{18}$

\section{Signs and Symptoms}

Varied symptoms can occur as a result of kidney transplant, including local (graft pain and tenderness, and local swelling over the graft $)^{10}$ and systemic (fever, tachycardia, hypotension, and tachypnoea). ${ }^{10}$ Signs may be masked because of immunosuppression and analgesics. A high index of suspicion is warranted in a patient with high drain output. $10,19,20$

\section{Investigations}

The following investigations are helpful in evaluating extraperitoneal urine leak post kidney transplantation, and to rule out differential diagnoses: 
> Compare drain creatinine and potassium levels with serum creatinine and potassium levels..$^{21-23}$

> Use ultrasonography to identify and define the perinephric collection and dilatation of the pelvicalyceal system. ${ }^{18}$

$>$ Doppler ultrasonography can be used to identify defects in perfusion. ${ }^{18}$

> CT or MRI scans are a useful tool to identify and define the perinephric collection and pelvicalyceal dilatation. ${ }^{18}$

>An intravenous pyelogram may be helpful to identify location of the leak. ${ }^{18}$

> Focal tracer scintigraphy uses mercaptoacetyltriglycine or technetium 99 to identify the location of the leak. This technique is not useful if there is delayed graft function or ureteral stasis. ${ }^{24,25}$

> Retrograde cystography helps clinicians to look for urinary bladder dehiscence. ${ }^{24,25}$

> Antegrade pyelogram testing through a nephrostomy may accurately identify the location of the leak. This can be done in delayed graft function scenarios too. Pelvicalyceal dilatation makes it easier to do this procedure. ${ }^{26}$

\section{Identifying Extraperitoneal Urine Leak Post Kidney Transplantation}

A high volume of clear drain fluid may indicate the possibility of extraperitoneal urine leak. Ultrasonography, CT scan or MRI, and fluid biochemistry further aid diagnosis. If drain fluid creatinine and potassium values are not dissimilar from the serum values, then the possibilities of lymphocele or seroma are higher. However, if they are significantly higher than the serum values, or are values that are incompatible with life, then it is a urine leak or urinoma. Urinoma will easily be picked up on an ultrasound scan or nuclear scan (Figure 1). Antegrade pyelogram, cystogram, or scintigraphy may be required to identify the cause and to localise the leak. ${ }^{27}$

\section{DIFFERENTIAL DIAGNOSIS AND CLINICAL REASONING}

\section{Haemorrhage}

If the drain is haemorrhagic, with accompanying factors like tachycardia, anaemia, local swelling over the graft, or if bleeding is a possibility, ultrasonography, CT scan, or MRI may be used to identify haematoma, necessitating an emergency re-exploration. 22,28,29 Haemorrhage is not a common complication after kidney transplantation. If it occurs, it is usually from the vessels in the graft hilum that are not ligated, or from small, severed retroperitoneal vessels. There are some recipient- and therapy-related risk factors that can predispose recipients to the risk of haemorrhage. These risk factors include recipient obesity, use of antiplatelet agents, and anticoagulation. ${ }^{10}$

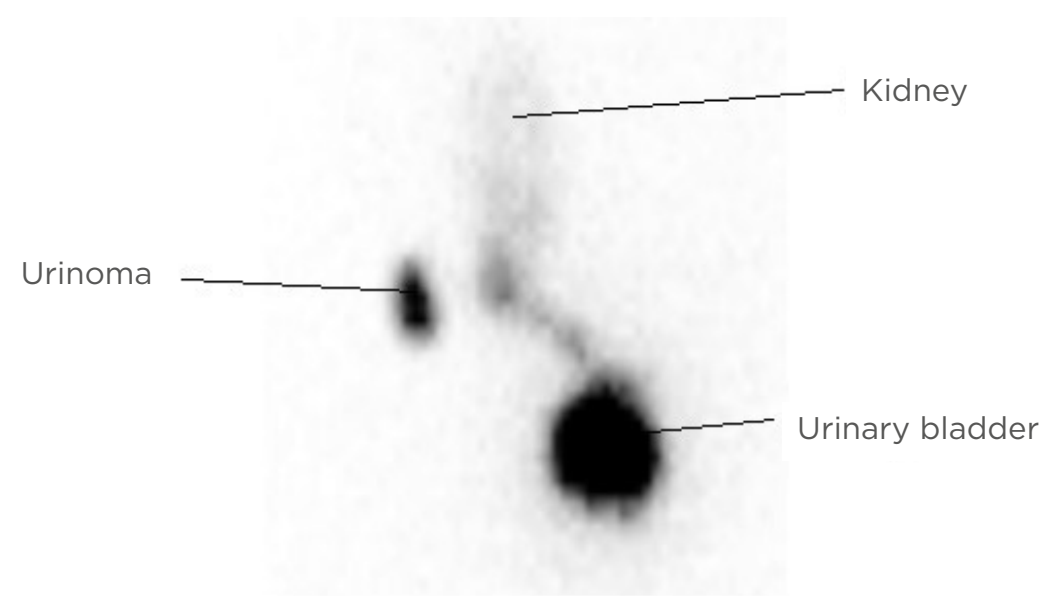

Figure 1: Urinoma, as seen in focal tracer scintigraphy using mercaptoacetyltriglycine. 
Serial measurement of haematocrit may show a falling haematocrit level. The patient may develop hypotension, tachycardia, and pain in the flank or lower quadrant. Surgical exploration is usually not required because bleeding usually stops spontaneously. However, if the patient needs pure red blood cell transfusion repeatedly, or if there is haemodynamic instability or compression of the kidney by haematoma, surgical re-exploration may be required. ${ }^{1}$

\section{Urinary Fistula}

Urinary fistula occurs in $2-5 \%$ of kidney transplantations, and may lead to significant morbidity, graft loss, and mortality; ${ }^{30,31}$ there is an $8 \%$ risk of mortality associated with urinary fistula. ${ }^{30}$ Ureteral ischaemia and necrosis and technical problems associated with the transplant procedure are important causes of urinary fistula development. ${ }^{30}$ The risk factors associated with development of urinary fistula include younger recipient age (aged $<10$ years), uretero-ureteric anastomosis, use of high-dose steroids in immunosuppression, number of renal arteries, and bladder problems. ${ }^{30}$ Early intervention helps to prevent graft loss and reduces mortality. ${ }^{30}$ Urinary fistulas may be managed by different techniques including ureteral ligature and nephrostomy, ureteroureterostomy, pyeloureterostomy, ureteroneocystostomy, percutaneous nephrostomy and ureteral stenting, and prolonged vesical drainage. ${ }^{30,31}$

\section{Perinephric Abscess}

Perinephric abscesses are uncommon complications post kidney transplantation. They usually present in the early post-transplant period (in the first few week's post-transplant). The causes include pyelonephritis, infection of lymphocele, haematoma, or urinoma. ${ }^{32}$ If the drained fluid is purulent, with accompanying symptoms and signs (fever, swelling, and tenderness over the graft), ultrasonography, CT scan, or MRI may aid the diagnosis of perinephric abscess. Aspiration of the collection and performing microscopy and culture of the aspirate may further help the diagnosis. ${ }^{28,29}$

\section{Lymphocele and Seroma}

A collection of lymph in the perigraft area is called a lymphocele. Lymphoceles occur in 1-20\% of kidney transplant operations. ${ }^{33}$ Lymphocele may occur from as early as 2 weeks to as late as 5 years post-transplant. ${ }^{33}$ Usually they are small and asymptomatic, and such lymphoceles require no intervention. ${ }^{33}$ Lymphoceles may present with features of compression symptoms including retention of urine, decreased urine output, elevated serum creatinine, thrombosis of iliac vein, and limb oedema. ${ }^{33}$ It is believed that lymphocele formation occurs because of technical failures to seal perivascular lymphatic channels incised during surgical exposure of the iliac vessels, or because of lymph leakage from the hilum of the allograft itself. Investigators have also found an association between sirolimus use and occurrence of lymphoceles and seromas. ${ }^{34}$

In lymphocele and seroma, the drainage fluid is clear. Ultrasonography, CT scan, or MRI, and fluid biochemistry further aid diagnosis. If drain fluid creatinine and potassium values are not much different from the serum values, then the possibilities of lymphocele or seroma are higher. ${ }^{28,29}$ Treatment options include aspiration (nearly $100 \%$ chances of recurrence), percutaneous drainage (50\% success rate), drainage by laparoscopic method, or open marsupialisation. ${ }^{33}$ Laparoscopic drainage of the lymphocele is the method of choice for the treatment of post-transplant lymphocele. However, open drainage is preferred over laparoscopic technique in patients with wound complications. Open drainage is also preferred over laparoscopic technique in patients with a small lymphocele adjacent to vital renal structures, which increases the risk of vessel or ureter injury. ${ }^{35}$ If the lymphocele is lateral to the renal allograft, laparoscopic drainage is usually difficult. ${ }^{36}$ Continuous drainage may be used together with the application of sclerosants like povidone iodine, fibrin glue, and doxycycline, tetracycline, ethanol, bleomycin. ${ }^{33,36}$ Periureteral fibrosis is a risk if sclerosing agents are used. ${ }^{36}$

\section{Urine Leak and Urinoma}

Urine leak is an early post-operative complication after kidney transplantation and occurs in 1.2-8.9\% of cases. $^{33}$ Urine leaks post kidney transplantation may manifest as free fluid (urine ascites), extravasation in local tissues, or may be encapsulated (urinoma). ${ }^{37}$ 


\section{Different clinical presentations of urine leak}

The different clinical presentations could be early extraperitoneal high-volume leak; early extraperitoneal small leak, defined by a persistent low urine output through drains, associated with low urine output, graft site swelling, and pain (imaging with contrast may help identify urinoma); late leak (1-2 weeks after kidney transplant), which may be caused by ureter necrosis or early removal of double J stent $(<3-6$ weeks); and intra-abdominal leak, which presents with an acute abdomen. 18,38

\section{Evidence-based management plan in extraperitoneal urine leak}

Low-volume leak at the anastomotic site can be managed conservatively by performing maximum decompression. ${ }^{39,40}$ Antegrade pyelogram to identify the site of the leak is helpful. Placing a Foley catheter and ureteral stent performing a nephrostomy are the techniques used for decompression. ${ }^{39,41}$ Once the urine leak stops, the Foley catheter and nephrostomy tube can be removed; however, the ureteral stent is only removed after a period of 4-6 weeks. ${ }^{41}$ After conservative management, the patient is carefully followed-up.39 If the fluid collections become infected, or cause ureteral obstruction and extrinsic compression on the ureter, then urgent percutaneous drainage is required. ${ }^{39,41}$ Surgical re-exploration and reimplanting the transplant ureter becomes necessary if conservative measures for stopping low-volume urine leak fail, or if there is a high-volume drain. $8,39-43$

\section{Preventive measures: importance of the golden triangle}

Urine leak usually occurs because of technical errors in the ureteroneocystostomy technique, the method of graft ureter implantation in the recipient's urinary bladder, or because of the transplanted ureter's compromised vascularity, which is caused by vessel damage during the harvest of the donor kidney. ${ }^{41}$ Presence of multiple renal arteries is also a risk factor for development of urological complications post kidney transplantation. ${ }^{41}$ During harvesting of the donor kidney, gentle handling of the ureter at the time of ureteral dissection is crucial to prevent urine leak post kidney transplantation. An adequate periurethral tissue in the 'golden triangle' must be carefully preserved:43,44,45-48 the 'golden triangle' is bound by the lower border of the junction between the renal vein and the inferior vena cava on the right, lower pole of the kidney on the left and the gonadal vein. ${ }^{43,44}$ Important factors that help to prevent major urological complications include delicate dissection of the ureter during donor nephrectomy to preserve adventitia; fat and blood supply of the ureter; short ureter length; and fixation of the adventitia, fat, and blood supply of the ureter to the bladder wall to prevent kinking or twisting. ${ }^{49}$

\section{Outcome of extraperitoneal urine leak: short-term and long-term effects on graft function and survival}

Surgical complications can cause graft loss post kidney transplantation. ' Several studies have shown that urological complications post kidney transplant may lead to prolonged hospitalisation and reduced graft survival (see Table 1). Buggs et al. ${ }^{50}$ conducted a retrospective cohort study of consecutive adult kidney transplant recipients and identified 36 cases of urine leak out of 1,308 cases. These investigators found that the patients with urine leak had a statistically significant longer length of hospital stay, more readmissions, more delayed graft function, and lower rates of graft survival. ${ }^{50}$ In another observational cross-sectional study of 3,102 kidney transplant patients, Carvalho et al..51 found that surgical complications occurred in 527 (17.0\%) patients and urinary complications in 184 (5.9\%). The most common complications observed were ureteral obstruction (in 85 patients; 2.7\%) and urinary fistula (in 72 patients; $2.3 \%$ ). They observed that surgical complications after kidney transplants lead to prolonged hospitalisation and decreased graft survival. ${ }^{51}$ Though most of the studies show similar results, some have also shown conflicting results (see Table 1)..$^{50-54}$

\section{CONCLUSION}

Different ureteroneocystostomy techniques, including the Lich-Grégoir, Politano-Leadbetter, and $U$-stitch techniques, have an impact on development of urine leak. The Lich-Grégoir technique has a significantly lower incidence of urinary leakage compared to the PolitanoLeadbetter procedure. 
Table 1: Impact of urological complications post kidney transplant on duration of hospitalisation and graft survival.

\begin{tabular}{|c|c|c|c|}
\hline Study & Total number of patients & $\begin{array}{l}\text { Number of patients with } \\
\text { urological complications }\end{array}$ & Investigators' observations \\
\hline Buggs et al., 502019 & 1,308 & 36 (2.75\%), urine leak & $\begin{array}{l}\text { Prolonged hospitalisation, more } \\
\text { readmissions, increased rate of } \\
\text { delayed graft function, and lower } \\
\text { rates of graft survival. }\end{array}$ \\
\hline Carvalho et al.,51 2019 & 3,102 & $\begin{array}{l}184(5.93 \%), \text { urinary } \\
\text { complications }\end{array}$ & $\begin{array}{l}\text { Prolonged hospitalisation and } \\
\text { decreased graft survival. }\end{array}$ \\
\hline van Roijen et al.,52 2001 & 695 & $\begin{array}{l}42(6.04 \%) \text {, required } \\
\text { revision of vesicoureteral } \\
\text { anastomoses }\end{array}$ & $\begin{array}{l}\text { No effect on long-term graft } \\
\text { survival by a surgically treated } \\
\text { urological complication within } \\
\text { 1-year post transplantation. }\end{array}$ \\
\hline Pillot et al., ${ }^{53} 2012$ & 200 & $\begin{array}{l}49(24.50 \%), 66 \text { surgical } \\
\text { complications in } 49 \text { patients, } \\
\text { with the majority being } \\
\text { urological complications }\end{array}$ & $\begin{array}{l}\text { Increased incidence of delayed } \\
\text { graft function and graft rejection } \\
\text { episodes among patients with } \\
\text { surgical complications. No impact } \\
\text { on patient or graft survival. }\end{array}$ \\
\hline Kaskarelis et al., ${ }^{54} 2008$ & 21 & $\begin{array}{l}21 \text { ( } 9 \text { with urinary leak, } 6 \\
\text { with ureteric obstruction, } \\
\text { and } 6 \text { with obstruction } \\
\text { preceded by leak) }\end{array}$ & $\begin{array}{l}\text { No impact on patient and graft } \\
\text { survival. }\end{array}$ \\
\hline
\end{tabular}

Technical errors in ureteroneocystostomy techniques or compromised vascularity of the transplanted ureter, caused by damage of the vessels during harvesting the donor kidney, are usually responsible for urine leak. Presence of multiple renal arteries is also a risk factor for development of urological complications post kidney transplantation.

A high index of suspicion is needed to identify the complications as the symptoms and signs may be masked because of the immunosuppressive drugs and the analgesics used. The colour of the drained fluid (haemorrhagic, clear, or purulent) and odour (uriniferous or foul) may indicate the development of a urological complication. If drain fluid is clear and the creatinine and potassium values are not much different from the serum values, then the possibilities of lymphocele or seroma are higher. If drain fluid is clear and drain fluid creatinine and potassium values are significantly higher than the serum values, then it is a urine leak or urinoma. Ultrasonography, CT, or MRI may help to arrive at a diagnosis. Doppler ultrasonography, contrast pyelogram, focal tracer scintigraphy using mercaptoacetyltriglycine or technetium 99, and retrograde cystography may be useful.

Extraperitoneal low-volume urine leak may be managed conservatively. Conservative management includes Foley catheterisation, nephrostomy, and placement of an antegrade ureteric stent. If conservative management fails, or if there is extraperitoneal high-volume leak, then surgical exploration and correction may become necessary. The ischaemic or necrosed part of the ureter needs to be removed, followed by reimplantation of the ureter. Development of urine leak may be associated with significant longer length of hospital stay, more readmissions, more delayed graft function, and lower rates of graft survival. If conservative management is used to manage the urine leak, prolonged followup may be necessary. 


\section{References}

1. Humar A, Matas AJ. Surgical complications after kidney transplantation. Semin Dial. 2005;18(6):505-10.

2. Alberts VP et al. Ureterovesical anastomotic techniques for kidney transplantation: a systematic review and meta-analysis. Transpl Int. 2014;27(6):593-605.

3. Sinh TN, Chuan HK. Modified Lich-Grégoir technique in renal transplantation by assisted peroperative transvesical cystoscopy: 2327. Transplantation. 2012;94(10S):921.

4. Lee RS et al. Ureteral complications in renal transplantation: a comparison of the Lich-Grégoir versus the Taguchi technique. Transplant Proc. 2007;39(5):1461-4

5. Friedersdorff $F$ et al. The ureter in the kidney transplant setting: ureteroneocystostomy surgical options, double-J stent considerations and management of related complications. Curr Urol Rep. 2020;21(3)

6. Haberal M et al. Surgical complications after kidney transplantation. Exp Clin Transplant. 2016;14(6):587-95

7. Wilson $\mathrm{CH}$ et al. Routine intraoperative ureteric stenting for kidney transplant recipients. Cochrane Database Syst Rev. 2013:6:DOI:10.1002/14651858. CD004925.pub3.

8. Veeratterapillay $\mathrm{R}$ et al. Management of urine leak following renal transplantation: an evidence-based approach. J Urol Nephrol. 2018;4(1):15.

9. Nie ZL et al. Treatment of urinary fistula after kidney transplantation. Transplant Proc. 2009;41:1624-6.

10. Ramirez CGB, "Kidney transplantation: surgical complications", Ramirez C, McCauley $\mathrm{J}$ (eds), Contemporary Kidney Transplantation (2018). Springer: Berlin, Germany. DOI:10.1007/978-3319-14779-6_15-1.

11. Mishra SK et al. Kidney transplantation in abnormal bladder. Indian J Urol. 2007:23:299-304.

12. Leong $K G$ et al. Renal transplant ultrasound: the nephrologist's perspective. Australas J Ultrasound Med. 2015;18(4):134-42.

13. Kolofousi $\mathrm{C}$ et al. Ultrasonographic features of kidney transplants and their complications: an imaging review. ISRN Radiol. 2012;2013:480862

14. Gunawansa N et al. Post-transplant urinary leak; the perennial 'Achilles heel' in renal transplant surgery. 2018;11(2):2-4.
15. Fernando $\mathrm{MH}$ et al. Complete necrosis of graft ureter following renal transplant in a patient with primary antiphospholipid syndrome: a case report. Clin Case Rep. 2018;6(7):13303.

16. Ogawa $Y$ et al. Posttransplant urine leakage with extensive ureteral stricture corrected by pyelopyelostomy: a challenging case. JOJ Uro Nephrol. 2019;6(3):555690.

17. Cassini MF et al., "Surgical complications of renal transplantation, surgica complications of renal transplantation", Ortiz J, Andre J (eds), Understanding the Complexities of Kidney Transplantation (2011). IntechOpen: London, UK. DOI:10.5772/16767.

18. Mohanka R et al. Practical approach to urine leak after kidney transplant. J Egypt Soc Nephrol Transplant. 2019;19:24-9.

19. Patri P et al. Vaccines for kidney transplant recipients: efficacy considerations and recommendations. $\mathrm{Br} J$ Renal Med. 2019;24(1):21-7.

20. Chitralli DK et al. IgA vasculitis in a patient on dialysis. Asian J Res Nephrol. 2020;3(1):17-23.

21. Mah TJ et al. Ureteric complications in recipients of kidneys from donation after circulatory death donors. Clin Transplant. 2017;31(4):DOI:10.1111/ ctr.12912.

22. Sui $\mathrm{W}$ et al. Timing and predictors of early urologic and infectious complications after renal transplant: an analysis of a New York statewide database. Exp Clin Transplant. 2018;16:665-70.

23. Flores-Gama F et al. Determination of creatinine in drained liquid. Urinary leak or lymphocele? Cir Cir. 2010:78:327-32.

24. Son $\mathrm{H}$ et al. Extraperitoneal urine leak after renal transplantation: the role of radionuclide imaging and the value of accompanying SPECT/CT - a case report. BMC Med Imaging. 2010;10:23.

25. Dirlik $A$ et al. Diagnosis of urinary leakage in renal transplant patients: ultrasonographic, clinical and scintigraphic findings. J Turk Soc Nephrol. 2001;10(4):239-43.

26. Kumar S et al. Ureteral obstruction following renal transplantation: causes, diagnosis and management. $\mathrm{Br}$ J Radiol. 2014;87:20140169.

27. Hamouda M et al. Urine leak after kidney transplant: a review of the literature. Exp Clin Transplant. 2018;16(1):90-5.

28. Singer J et al., "The transplant operation and its surgical complications", Danovitch GM (ed), Handbook of kidney transplantation
(2005) $5^{\text {th }}$ edition. Lippincott Williams \& Wilkins: Philadelphia, Pennsylvania, USA, pp.193-212.

29. Shoskes D, Jiménez JA, "Urological complications after kidney transplantation", Morris PJ, Knechtle SJ (eds), Kidney transplantation: principles and practice (2013) $7^{\text {th }}$ edition. Saunders: Oxford, UK, pp.464-71.

30. Mazzucchi E et al. Primary reconstruction is a good option in the treatment of urinary fistula after kidney transplantation. Int Braz J Urol. 2006;32(4):398-404.

31. Batagello $\mathrm{C}$ et al. Ligation of the native ureter for treatment of urinary fistula in kidney transplantation: is it safe? Abstract C222. 2015 American Transplant Congress, 4 May, 2015.

32. Alshamsi l et al. Perinephric transplant fluid collection approach and management. Saudi J Kidney Dis Transpl. 2019;30:564-70.

33. Sabnis RB et al. The development and current status of minimally invasive surgery to manage urological complications after renal transplantation. Indian J Urol. 2016;32(3):186-91.

34. Valente JF et al. Comparison of sirolimus vs. mycophenolate mofetil on surgical complications and wound healing in adult kidney transplantation. Am J Transplant. 2003;3(9):1128-34

35. Fuller TF et al. Management of Iymphoceles after renal transplantation: laparoscopic versus open drainage. J Urol. 2003;169(6):2022-5

36. Duty BD, Barry JM. Diagnosis and management of ureteral complications following rena transplantation. Asian J Urol. 2015;2(4):202-7.

37. Ginanni B et al. Urine leaks and urinomas: causes, diagnosis and imaging features. Poster C-1087. ECR 2011, 3-7 March, 2011

38. Kamaraj $\mathrm{K}$ et al. Post-operative surgical complications after kidney transplantation - a nephrologist's perspective. J Renal Transplant Sci. 2019;2(2):99-108.

39. Chughtai SA et al. Urine leak following kidney transplantation: an evidence-based management plan. $J$ Clin Exp Nephrol. 2018;3(3):14.

40. Elsayed S. Early urological complications post kidney transplant. Urol Nephrol Open Access J. 2020;8(1):1-4

41. Sujeet P. Current insights on urinary leak in renal transplantation. Exp Tech Urol Nephrol. 2020;3(1)

42. Buresley S et al. Postrena transplantation urologic 
complications. Transplant Proc. 2008;40:2345-6.

43. Buttigieg $\mathrm{J}$ et al. Early urological complications after kidney

transplantation: an overview. World J Transplantation. 2018;8(5):142-9.

44. Gopalakrishnan G. Surgical aspects of renal transplantation: contributions to solutions for complex problems. Saudi J Kidney Dis Transpl. 2002;13:451-9.

45. Indu $\mathrm{KN}$ et al. Is early removal of prophylactic ureteric stents beneficial in live donor renal transplantation?. Indian J Nephrol. 2012;22:275-9.

46. Arvind NK, Kumar A. Laparoscopic live donor nephrectomy: an indian perspective. Indian J Urol. 2002;19:29-37.
47. Dinckan A et al. Early and late urological complications corrected surgically following renal transplantation. Transplant Int 2007;20(8):702-7.

48. Breda A et al. EAU Guidelines on male infertility. 2018. Available at: https://uroweb.org/wp-content/ uploads/EAU-Guidelines-on-MaleInfertility-2018-large-text.pdf. Last accessed: 17 November 2020.

49. Davari HR et al. Urological complications in 980 consecutive patients with renal transplantation. Int J Urol. 2006;13(10):1271-5.

50. Buggs $\mathrm{J}$ et al. Repair of ureteral leaks post-kidney transplantation. Am Surg. 2019;85(8):e380-2.
51. Carvalho JA et al. Surgical complications in kidney transplantation: an overview of a Portuguese reference center. Transplant Proc. 2019;51(5):1590-6.

52. van Roijen JH et al. Long-term graft survival after urological complications of 695 kidney transplantations. J Urol. 2001;165(6, Part 1):1884-7.

53. Pillot $P$ et al. Risk factors for surgical complications after renal transplantation and impact on patient and graft survival. Transplant Proc. 2012;44(9):2803-8.

54. Kaskarelis I et al. Ureteral complications in renal transplant recipients successfully treated with interventional radiology. Transplant Proc. 2008;40(9):3170-2. 